\title{
Uses of Social Networking Sites and Satisfactions Achieved by Emirati Youth: A Field Study on a Sample of Sharjah University Students
}

\author{
Fawzia Abd Allah Al-Ali \\ Sharjah University, Sharjah, United Arab Emirates
}

\begin{abstract}
The study, throughout the usage of Emirati youth for the social networking sites and satisfactions achieved, illustrated that the nature of those networks is considered a rapidly developing method of communication, which is accompanied by attempts to impose a number of short abbreviated vocabulary to be used among the youth. Since social networking sites represent one of the most significant tremendous development aspects of information technology, which reached its peak during the last decade, the researcher considered the importance of conducting this study in order to know the impact of social networking sites on the youth through Internet, blogs and chat rooms, as well as attempting to confront them and making them aware of their importance in their daily lives. Accordingly, the study has focused on a random category of youth, whose ages are ranging between 17-21 years old of university students, as being the highest category of usage. Results revealed the following: A high percentage of Emirati youth $77.5 \%$ mentioned that they "always" use those sites; the percentage of males, who "always" use social media reached $38.5 \%$ while the percentage of females reached 61 , since the meaningful value reached $0.05>0.044$, which indicated that WhatsApp, YouTube, Twitter and Facebook are the most commonly used social media by the study individuals. Most of the study individuals use the social networking sites daily $84 \%$, and there are statistically significant differences between males and females in terms of the times of using social media. A high percentage of the Emirati youth uses Internet for more than three hours daily; especially in the evenings, and there are not statistically significant differences between males and females in terms of the most common periods in which social media are used, and the most common age groups of using social media from one year and more range between 17-20. "Home" is the most favorite place of using social media (85.40\% mentioned that). Most of the study individuals can make a balance between spending time on Internet and spending time with people outside the world of Internet. The percentage of those, who mentioned that social networking sites affected them positively, was higher than the percentage of the ones, who mentioned that the social media affected them negatively. Among the most prominent usages of social media by the Emirati youth are: staying informed about news and current events, while most of them focused on chatting, followed by sharing photos and images. Most of the sample of study mentioned that the youth are just readers, who comment on what is shared and posted on the social media. The most prominent motives of the Emirati youth for using social media are represented in obtaining information, and communicating with others, which came on top of the motives relevant to the usage of social media, followed by entertainment, education, followed by various motives, including routine etc. Some of the most significant
\end{abstract}

Fawzia Abd Allah Al-Ali, Ph.D., Head of the Dean of The Mass Communication Department, Faculty of Communication, Sharjah University. 
satisfactions achieved through using the social networking sites by the Emirati youth are entertainment and spending leisure time with others.

Keywords: satisfaction, youth, social network

\section{Introduction}

Modern technological developments reached during the mid-nineties of the last decade resulted in a quantum leap and a real revolution in the world of communication. Internet has spread around the whole world and all parts of the world became connected together and it paved the way for societies to establish relations, exchange opinions, ideas and desires, and all users browsing the numerous available social networking sites benefited from it. Moreover, recent studies confirmed this meaning since the Internet resulted in a quantum leap in social relations and interactions. The study of Internet and its social effects on the individual and society levels, is considered a continuous demand through the subsequent changes occurring in the contemporary society; whether through the websites "Facebook", "Twitter" and their tools; such as group services and websites of this network and through all the daily established groups and information spread in order to satisfy the requirements of individuals to communicate with others, obtain information, establish relations and friendships etc. away from direct communication with the outer world (Tia, 2014).

Social networking sites represent a new communicational revolution and a special distinguished communicational entity established to survive, compete and impose its unique model on all those, who are concerned with human and social studies in general, and media in particular at a time though which this revolution has created new communicational entities, produced various distinguished communicational tools, introduced unprecedented research fields and gained attention of millions of traditional mass media users, and it has become difficult for a researcher in the field of media and communication not to put this new entity into consideration in terms of studying and teaching (Jennifer, 2014). Along with the increasing dependence of individuals on Internet and the development of websites, usages became variable; including the browsing of e-mails, followed by forums, chat rooms, text and instant messaging, and blogs until social networking sites appeared; such as the term referring to the group of websites, which appeared with the second generation of web and it facilitated communication with a virtual community; topmost of which are the Facebook - Xing Twitter - Myspace, and this resulted in $42 \%$ of youth using Internet. This provided users with a Virtual Interactive Environment and attracted an obvious space of youth's time, thought, attention, emotion and minds; especially after succeeding in attracting several age groups on all religious, political, economic and generic levels (Jennifer, 2014).

\section{Importance of Study}

The importance of the study:

(1) One of the most important studies attempting to get well acquainted with the capability of using social networking sites by the youth.

(2) It seeks to clarify the motives of using social networking sites for the youth.

(3) It seeks to know the satisfactions of social networking sites for the youth.

(4) It seeks to know the most important disadvantages of those social networking sites from the youth's point of view. 


\section{Previous Studies}

Esam Obaid's study titled The Role of Social networking sites in Supporting University Curricula from the Male and Female Students' Point of View on a research sample consisting of (100) male and female students from The Faculty of Computer Science and Information, Imam Mohammed Bin Saoud Islamic University, in order to know their attitudes towards social networking sites in terms of their academic curricula. He concluded that students are not sure about the importance of social networking sites in supporting university curricula, and professors do not accept attaching their personal websites or the ones of their educational sections to the web through social networking sites ${ }^{1}$.

Some studies revealed the negative role of social networking sites as shown in the study of Sangari, Limayem, and Rouis (2011). Its results indicated that Facebook does not have a significant role on students' academic performance, and results of Lei and Wu's (2007) study, which revealed the positive correlation between psychological isolation and the increasing number of hours spent on using Internet, as well as the results of Al-Amri (2008) study, which revealed some negative effects of Internet addiction; topmost of which are: sleep problems, depression, sadness due to Internet abandonment, tending toward isolation, avoiding others and telling lies in conversations and chats (Webb, 2014).

The study of Jamal Al-Minais (2015) paid special attention to the results related to the intensive use of social networking sites among the Kuwaiti youth, and it shed light upon the impact of social networking sites; such as Twitter and Instagram, on the Kuwaiti youth from social and psychological aspects. From the social aspect, the study dealt with the role of social networking sites in highlighting the phenomenon of "social substitution". It has shown that the intensive use of those social networking sites substitutes the time spent by an individual with family. Moreover, results have shown that social networking sites play a vital role in social relations with others. It is evident that the intensive use leads to a feeling that an individual's social life and friendships become better than before.

The study of Alice Hall (2009) (Kalpidou, Costin, \& Morris, 2011), which aimed at knowing the motives of university youth for using social networking sites and the relation with their personal characteristics, was carried out on a sample consisting of 101 individuals having at least one profile on one of the social networking sites and the study has reached several results including: $83 \%$ of the respondents have accounts on more than three of those sites; and Facebook occupied the first position among all sites tended to be used by the youth with a percentage of 55\%, followed by Myspace, with a percentage of 33\%. Regarding the motives of using social networking sites, the motive of "maintaining existing relations came on top of the other motives, followed by spending time, with an average of 3.28 , obtaining information and enhancing my relation with others respectively".

The study of Reda Amin (2009), which attempted to know the extent of using YouTube site by the university youth, motives of using it, satisfactions achieved through using this site, the level of youth's trust in it on a sample consisting of 122 individuals from university youth. The study reached several results; topmost of which are: $70.5 \%$ of the research sample do not know websites that are specialized in displaying and attaching video files other than YouTube, and 29\% of the respondents indicated that they know other websites; such as the Islamic YouTube, MASRAWY, and the most important motives of using YouTube are represented in knowing the top news, the rare TV shots and snapshots with a percentage of $31.7 \%$, for entertainment with a

${ }^{1}$ Kehbuma Langmia and Stella Monica Mpandde, Social Media and Critical Pedagogy, op.cit. 
percentage of $29.9 \%$, for watching parts of plays and TV programs with a percentage of $26.15 \%$, and being curious to know more about a new media pattern with a percentage of $20.5 \%$ (Sangari, Limayem, \& Rouis, 2011).

The study of Nermin Khedr (2009), sought to know the psychological and social impacts of using social networking sites by the Egyptian youth. The study aimed at knowing the motives of using Facebook site by the Egyptian youth, sample of study. It observed the most important activities performed by the youth on the website through a sample consisting of 136 individuals using Facebook site from university youth. The study reached several results, including: 50\% of respondents subscribed to Facebook for six months or more, 27.9\% for 3-6 months, $11.8 \%$ for one to two months, $10.3 \%$ for less than one month, and the most important motives of using Facebook are represented in entertainment with a percentage of $75 \%$, establishing new friendships $48.5 \%$, self-abreaction $19.1 \%$, communicating with others $42.6 \%$, and the psychological impacts of using Facebook site are represented in: "I do not feel lonely", "expressing myself freely", "feeling anxious and depressed", and the social impacts are represented in "getting rid of life pressures", "openness towards news of others", and "feeling bored" (Lei \& Wu, 2007).

The study of Urista and Others (2009) sought to know the use of social networking sites by the university youth through applying to both Myspace and Facebook sites. The study reached several results, including: The most important motives of using both sites by the university youth are represented in being an efficient method of communicating with others; it is also an easy and convenient method of communicating with families and friends. Subscribers indicated that they obtained lots of information on members without their knowledge (Al-Omari, 2008).

Among the studies that sought to interpret the use of youth for both (Facebook and Myspace Sites) within the framework of the uses and satisfactions introduction, the study of (Urista et al., 2009), which concluded that youth use both (Facebook and Myspace Sites) with the motive of keeping up with social events in the life of friends easily (Jamal Al-Minais, 2015).

\section{Comments on Previous Studies}

The comments on previous studies:

(1) The previous studies focused on studying the method of using social networking sites by the university youth due to several features and characteristics of university students, who are considered the goal for several researches.

(2) Most of these studies depended on the introduction of uses and satisfactions in knowing the average of using social media, the different motives of usage, satisfactions achieved through this usage and testing the role of demographic changes; especially age and gender in affecting the average of use, its resulting motives and satisfactions.

(3) Lack of studies, which combined both the social media and the method of benefiting from them in the educational process.

(4) Lack of studies, which attempted to explore the capabilities of social media as a media mediator and a curriculum to be taught for media students as being considered a distinguished media method.

(5) Contradiction of study results in terms of respondents' opinions on social networking sites, negative and positive aspects of those sites. 


\section{Theoretical Framework of the Study}

The introduction of Media Dependency is considered as one of the introductions that establish audience's relation with social media as the degree of individuals' dependency on the social media information is the basis of understanding the impact of media messages on the beliefs, feelings and behavior (Bălterețu \& Balaban, 2010).

Uses and Satisfactions: In this framework, researchers, based on empirical studies, derived several types of uses; topmost of which are: First: Uses relevant to information, while the second significant type of uses is relevant to what is called "event coordination"; such as organizing school meetings, social occasions, collecting money, religious occasions and birthday parties by using the "Event" Program, which is made available through Facebook. The third type of uses is related to the events of groups having common interests. These uses confirm that social networks have a strong relation with the daily life activities (Hall, 2009).

It is assumed through the introduction of uses and satisfactions that the individuals are driven through psychological and social impacts to use mass media in order to obtain special results called "satisfactions". Studies, which are conducted on uses and satisfactions, classified satisfactions into satisfactions of method, which develop from performing a method; such as creating a personal profile on social media, relaxation of tension, recreation and comfort, getting rid of boredom and isolation, satisfactions of content; such as obtaining information, discovering reality and combining both the information obtained by an individual through its social relations network; such as the ability to speak with others (Urista et al., 2009).

Adapting the model of innovative ideas dissemination to the study of media practitioners' uses for social media through knowing the extent of spread of those social media in media corporations, and studying this on two levels: The level of adoption through corporations, then the level of individual adoption as well as focusing on studying the impact of complication in terms of using those methods and their convenience on the possibility of adopting them, and putting the factors that affect adopting those new methods by the corporations into consideration (Sheldon, 2008).

The study attempts to benefit from this model in understanding the phenomenon of using social media and the satisfactions achieved in the field of studying media and the opinions of those, who use this method.

\section{Research Problem}

This study focuses on the extent of using social networking sites by the Emirati youth and the satisfactions achieved. The nature of those networks, as being one of the most rapid methods of communication that witnessed the attempts of imposing a number of abbreviated and shortened vocabulary to be used among the youth, and since the social networking sites represent one of the most significant aspects of tremendous development in information technology, which kept on progressing during the last decade, the researcher decided to carry out this study in order to know the extent of having an impact for social networking sites on youth through Internet, blogs, chatrooms, and trying to confront them, as well as making them aware of their importance in their daily lives. Thus, the study focused on a random category of youth, whose ages range between 17-21 years from university students, which is the top usage category.

\section{Defining Research Problem}

Defining Research Problem: 
First: The main objective of this study is to know the extent of using social networking sites by the youth in the United Arab Emirates. Second: Knowing the extent of impact for using those networks on the youth in the United Arab Emirates.

In order to achieve these objectives, the research is trying to answer the following questions:

(1) What are the traditions and patterns of using Internet and mobile phones by the students of Sharjah University?

(2) What are the sites used?

(3) What are the communication services made available by the network?

(4) What are the most used services?

(5) What are the satisfactions achieved by the youth through using these networks?

(6) What are the impacts of using social networking sites?

(7) What are the motives of using social media through the Internet by the youth?

(8) What are the most apparent disadvantages of social networking sites?

\section{Type and Approach of Study}

This study is considered a descriptive one that aims at collecting data related to the use of mass media students, sample of study, for social media and their attitudes towards using them, as well as studying some variables, which are related to usage; such as gender, social status, educational stage, etc. This study depends on the approach of survey as being considered an organizing scientific effort that is used for obtaining information or descriptions of the phenomenon, subject matter of study.

\section{Community and Sample of Study}

Community of the field study is determined according to its objectives and researchers' capabilities, male and female students of Mass Communication, Faculty of Communication, Sharjah University during the year 2015-2016 as those students represent the sample of community on the one hand, and it is supposed that they will be more interested in observing the use of social networking sites according to their specialization, on the other hand. The researcher decided to carry out this study through the method of comprehensive calculation for all male and female students of Mass Communication Section, Faculty of Communication, Sharjah University, and after applying the validity test to the forms, the number of valid forms was 200 forms.

The researcher in this study uses the Purposive Sample, as she chose cases in this type of samples that are believed to represent the society in terms of the aspect discussed in the research. Accordingly, the study is carried out on a purposive sample consisting of 200 individuals, (Media students from Sharjah University)—sample of study characteristics.

\section{Method of Collecting Data}

This study uses the questionnaire form as a method of collecting data, and it included the different aspects sought to be known by the study according to the objectives, questions and assumptions of study.

\section{Validity and Reliability Test}

In order to check the validity of the questionnaire form, its application validity and the extent of representing purposes of the study, it has been reviewed by a number of professors, who are specialized in the 
field of media, and amendments were made. In light of their instructions, some questions were rephrased; some were added, as well as conducting a pre-test to a $10 \%$ sample of respondents, and consequently, a number of phrases were rephrased in order to be more appropriate for the respondents, and thus, face validity of data is achieved.

In order to ensure data reliability, the researcher used the Test-Re-Test Method. The researcher re-applied 20 forms; i.e., an equivalent of $10 \%$ of the sample, and consistency reached 94 , which is a percentage that indicates clarity of the form, confidence in its validity to be finally applied, and thus, this form was applied during months of March, April and May 2015.

\section{Statistical Manipulation of Data}

Data is statistically manipulated by using computer via "the Statistical Package for the Social Sciences" Program SPSS, and the following statistical manipulations were conducted:

(1) Simple repetitions and percentages.

(2) Centennial weight.

(3) $\mathrm{T}$ - Test.

(4) Pearson Correlation Co-efficient.

\section{Results of Study}

Uses of Social Networking Sites and Satisfactions Achieved by Emirati Youth:

(1) Sample of Study Characteristics:

It is evident through the Figure 1 that the percentage of study individuals consists of males and females; females' percentage reached $61.50 \%$, while males' percentage reached $38.50 \%$ from the sample of study.

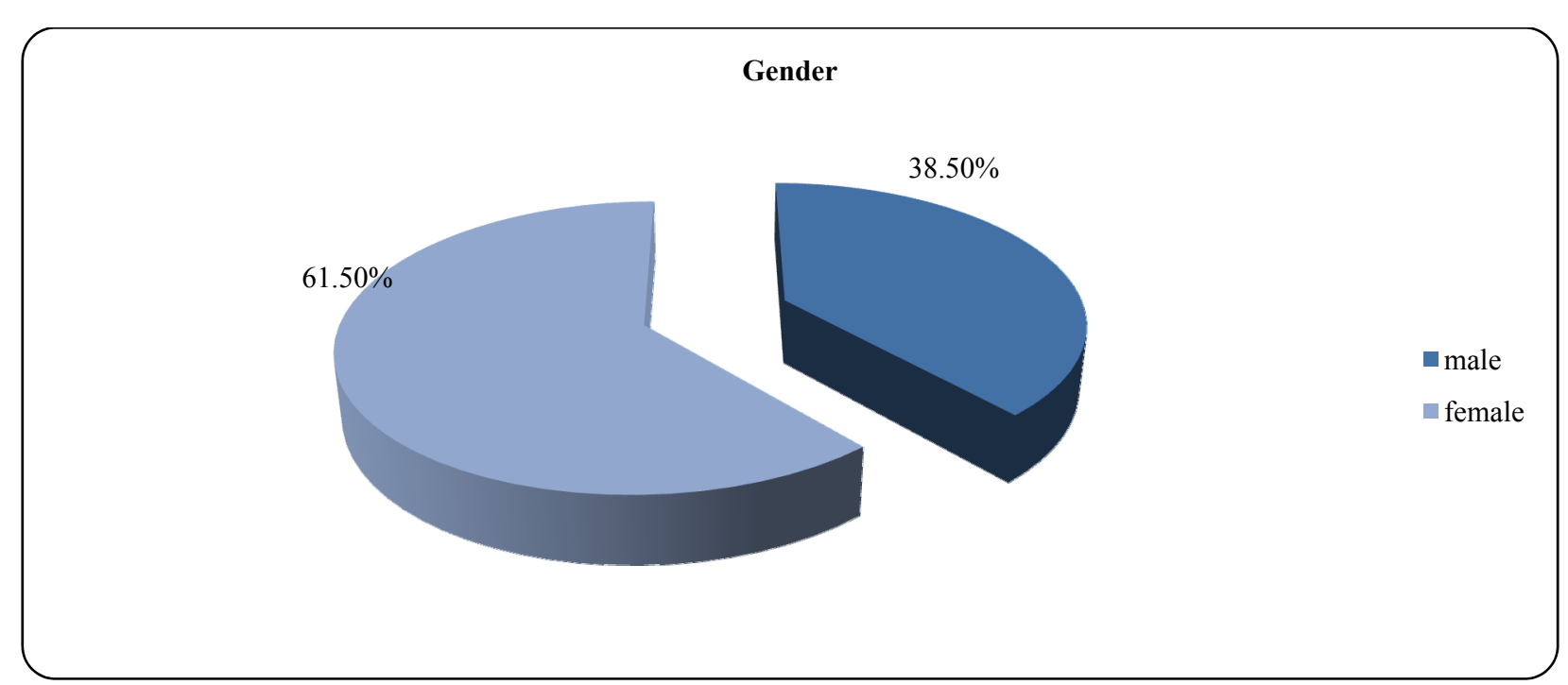

Figure 1. Sample of Study Characteristics.

(2) The Extent of Using Social Media:

Figure 2 shows the extent of using social media by the study individuals. $77.50 \%$ of them use those social media "Always", $16.50 \%$ of them use social media sometimes, and then rarely with a percentage of $3.50 \%$, and finally, "No", for individuals, who do not use social media reached $2.50 \%$. 


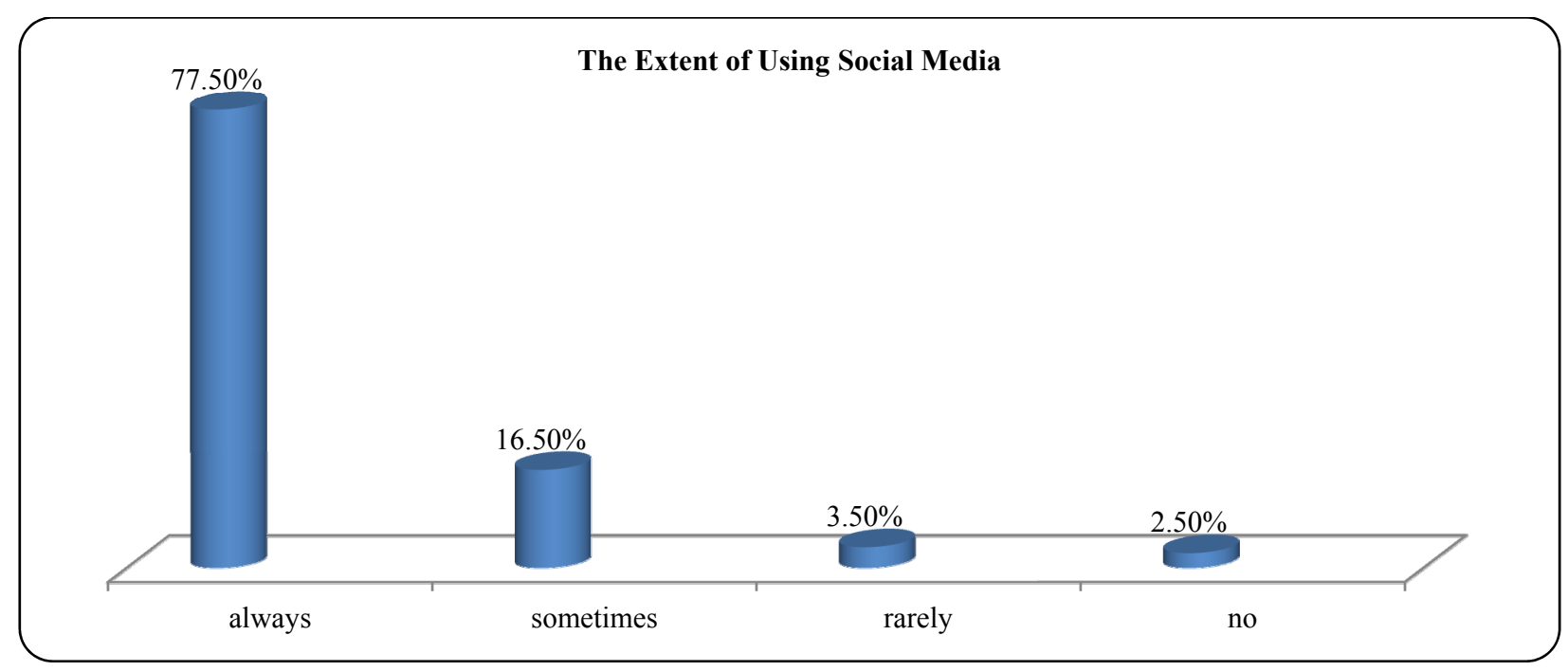

Figure 2. The Extent of Using Social Media.

Table 1

The Use of Social Media According to Gender

\begin{tabular}{|c|c|c|c|c|c|c|c|c|c|c|c|c|c|}
\hline Gender & & Always & & etimes & & rely & & No & & otal & Average & $\begin{array}{l}\text { T Value } \\
\mathrm{T} \text { Test }\end{array}$ & P Value \\
\hline & freq & $\%$ & freq & $\%$ & freq & $\%$ & freq & $\%$ & freq & $\%$ & & \multirow{4}{*}{2.025} & \multirow{4}{*}{0.044} \\
\hline Male & 55 & $27.5 \%$ & 13 & $6.5 \%$ & 7 & $3.5 \%$ & 2 & $1.0 \%$ & 77 & \multicolumn{2}{|c|}{$38.5 \% 1.43$} & & \\
\hline Female & 100 & $50.0 \%$ & 20 & $10.0 \%$ & 0 & $.0 \%$ & 3 & $1.5 \%$ & 123 & \multicolumn{2}{|c|}{$61.5 \% 1.24$} & & \\
\hline Total & 155 & $77.5 \%$ & 33 & $16.5 \%$ & 7 & $3.5 \%$ & 5 & $2.5 \%$ & 200 & \multicolumn{2}{|c|}{$100.0 \%$} & & \\
\hline
\end{tabular}

It is evident from Table 1 that the percentage of Males, who "Always" use social media reached $38.5 \%$ against Females with a percentage of $61 \%$, and the meaningful value reached $0.005>0.044$, and there are no statistically significant differences between males and females regarding the extent of using social media.

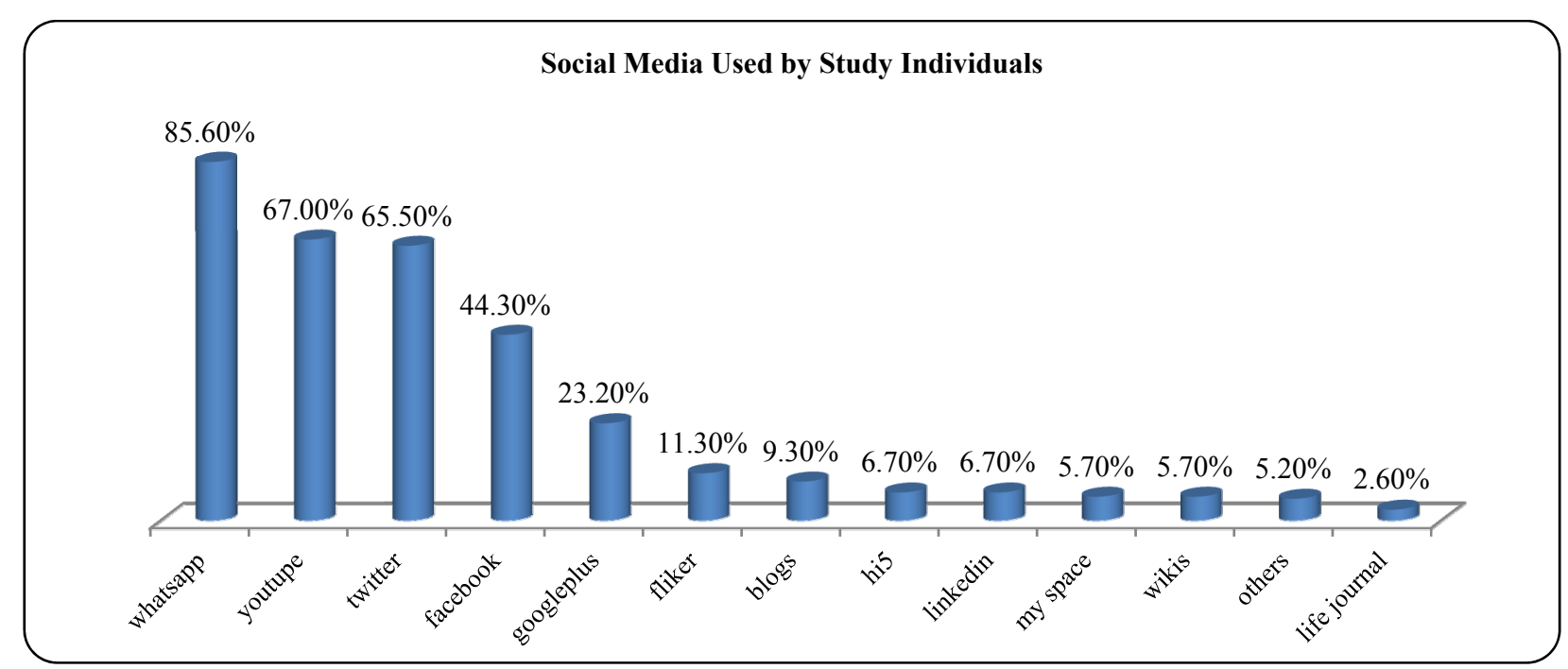

Figure 3. Social meadia used by study individual.

It is evident through Figure 3 that "WhatsApp, YouTube, Twitter and Facebook" are the most commonly used social media by the study individuals, and percentages reached $85.60 \%, 67.00 \%, 44.3 \%$, followed by 
Google plus with a percentage of $23.20 \%$, Flickr with a percentage of $11.30 \%$, blogs with a percentage of $9.30 \%$, hi5 with a percentage of $6.70 \%$, LinkedIn 6.70\%, Myspace 5.7\%, Wikis 5.70 and Live Journal $2.60 \%$.

This indicates that the sample tends to use WhatsApp with a high degree, which shows the extent of importance of WhatsApp in the process of communication among society individuals, exchanging news and information compared to other social networking sites. Results of this study contradict the results of the Study carried out on The Impact of Using Social Media by the University Youth in Private Bahraini Universities on Using Traditional Social Media (Abd El-Sadiq Hassan Abd El-Sadeq). This study has proven that the most important social networking site used is Facebook with a percentage of $83.41 \%$, followed by Twitter with a percentage of $45.35 \%$, and it conforms to a study on the social media conducted by each of: Khawla Al-Akl and others.

(3) The Periods Through which Social Media are used more than Other Periods:

Table 2

The Periods Through Which Social Networking Sites Are Used

\begin{tabular}{|c|c|c|c|c|c|c|c|c|c|c|c|c|c|c|c|}
\hline \multirow[t]{2}{*}{ Gender } & \multicolumn{2}{|c|}{$\begin{array}{c}\text { Morning } \\
\text { Period } \\
\end{array}$} & \multicolumn{2}{|c|}{ Noon Period } & \multicolumn{2}{|c|}{ Night Period } & \multicolumn{2}{|c|}{$\begin{array}{l}\text { Mid-Night } \\
\text { Period }\end{array}$} & \multicolumn{2}{|c|}{ Other } & \multicolumn{2}{|r|}{ Total } & \multirow[t]{2}{*}{ Average } & \multirow{2}{*}{$\frac{\mathrm{T} \text { Test }}{1.042}$} & \multirow{2}{*}{$\begin{array}{l}\text { P Value } \\
0.299\end{array}$} \\
\hline & freq & $\%$ & freq & $\%$ & freq & $\%$ & freq & $\%$ & freq & $\%$ & freq & $\%$ & & & \\
\hline Male & 9 & $4.5 \%$ & 4 & $2.0 \%$ & 45 & $22.5 \%$ & 15 & $7.5 \%$ & & $2.0 \%$ & 77 & $38.5 \%$ & 3.01 & & \\
\hline Female & 15 & $7.5 \%$ & 12 & $6.0 \%$ & 75 & $37.5 \%$ & 16 & $8.0 \%$ & & $2.5 \%$ & 123 & $61.5 \%$ & 2.87 & & \\
\hline Total & 24 & $12.0 \%$ & 16 & $8.0 \%$ & 120 & $60.0 \%$ & 31 & $15.5 \%$ & & $4.5 \%$ & 200 & $100.0 \%$ & & & \\
\hline
\end{tabular}

It is evident from Table 2 that males, who use social media, reached a percentage of $38.5 \%$ against females $61.5 \%$, and through statistical application, it is evident that there are no statistically significant differences between males and females in terms of the periods through which social media are used more than other periods since the meaningful value is $5.05<0.299$, and this value agrees with Al-Sadeq's result, the study of Dr. Ruhaima Eissany and Dr. Abd El-Sadeq Hassan.

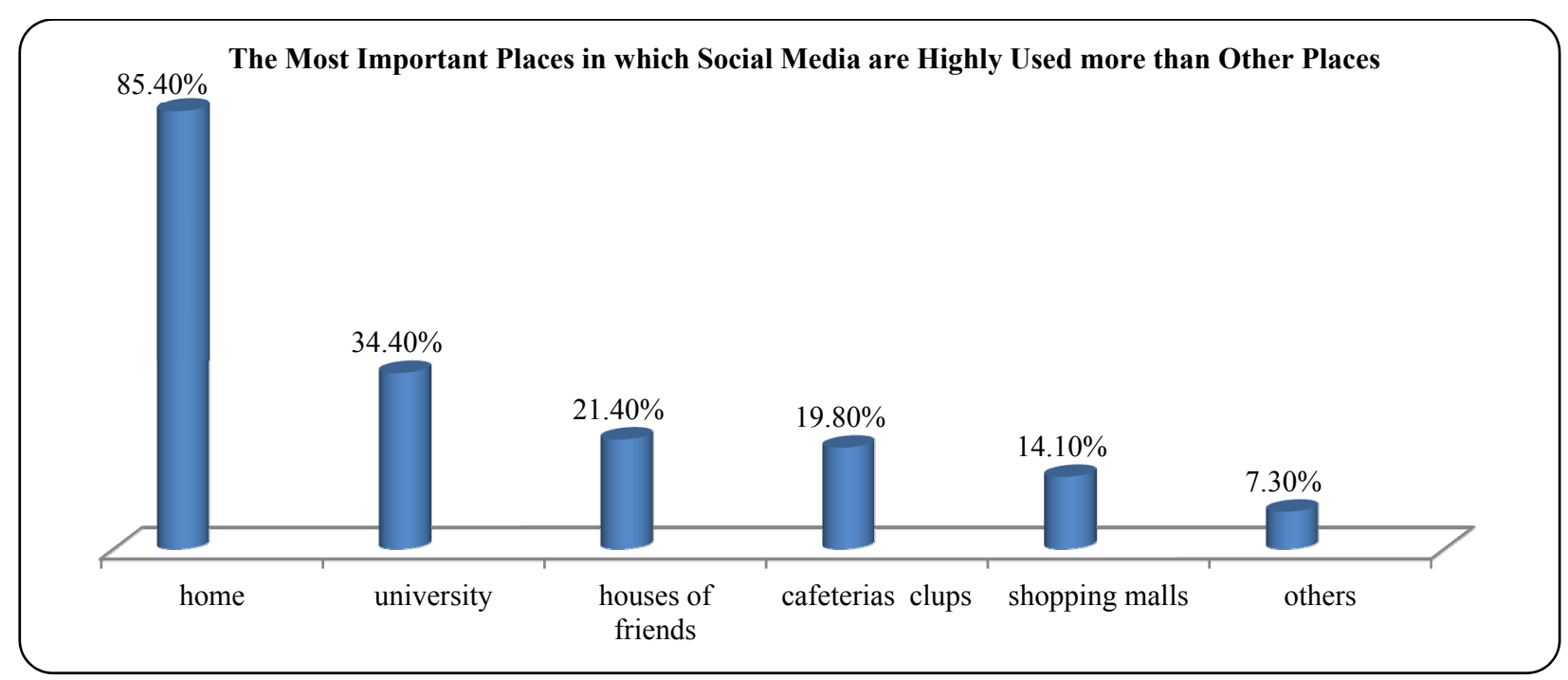

Figure 4. The most important places in which social media are highly used more than other places.

Figure 4 shows the most important places in which social media are used by the study individuals more than other places. It is evident that "home" is the most common place with a percentage of $85.40 \%$, then the 
"university" with a percentage of $34.40 \%$, then the "houses of friends", followed by "cafeterias and clubs" with a percentage of $19.80 \%$, "shopping malls" with a percentage of $14.10 \%$, and finally, "other" with a percentage of $7.30 \%$. This result agrees with results of the previous studies; including the study of Dr. Ruhaima. This indicates that the "house" is the most important place in which the sample prefers to use the social networking sites as it ensures quietness and privacy.

Table 3

The Preferred Places to Sit

\begin{tabular}{lrr}
\hline Preference categories & freq & $\%$ \\
\hline I can make a balance between spending time on the Internet and spending time with people outside & 130 & 65.0 \\
the world of Internet. & 49 & 24.5 \\
I Prefer mixing with people rather than using social media. & 21 & 10.5 \\
I prefer social media rather than mixing with people in reality. & 200 & 100.0 \\
Total & \\
\hline
\end{tabular}

It is evident through Table 3 that most of the study individuals can make a balance between spending time on the Internet and spending time with people outside the world of Internet with a percentage of $65 \%, 24.5 \%$ of them prefer mixing with people in the reality rather than using social media, and finally, $10.5 \%$ of them prefer social media rather than mixing with people in reality. This result indicates that most of the sample individuals prefer using Internet for spending leisure time rather than spending time with people.

(4) The extent of Impact of Social Networks on Relations of the Study Individuals in Reality:

Table 4

The Extent of Impact of Social Networks on Relations of the Study Individuals in Reality

\begin{tabular}{lrr}
\hline Extent of impact & freq & $\%$ \\
\hline Affected positively through enhancing the skill of communicating with others. & 104 & 52.0 \\
No Impact Whatsoever. & 66 & 33.0 \\
Made me unsociable and unwilling to mix up with people. & 16 & 8.0 \\
Affected negatively through spending more time on them and led to the loss of some friendships. & 14 & 7.0 \\
Total & 200 & 100.0 \\
\hline
\end{tabular}

Table 4 shows the extent of impact relevant to social networks on relations of the study individuals in reality. The percentage of those, who are positively affected is $52 \%$ as they enhanced the skill of communicating with others, $33 \%$ of them had no impact whatsoever, then $8 \%$ of them became unsociable and do not like mixing up with others, and finally, they affected negatively a percentage of $7 \%$ since they spent more time using them, which indicates that the most important impacts of social media on the sample individuals are represented in enhancing the skill of communicating with others.

(5) Reasons of Using Social Media by the Study Individuals:

It is evident through Table 5 that the reasons of using social media by the study individuals are ordered as follows:

They "enable viewing news, information and opinions first and foremost" with a percentage of $82.2 \%$, followed by "Help establish social relations and bonds" $69.6 \%$, followed by "I like interacting, discussing and speaking with colleagues and network users with a percentage of $62.2 \%$ ", followed by "For employing several tools including texts, images and videos, etc." with a percentage of $58.1 \%$, followed by "They help me know the interests of others" with a percentage of 52.4, followed by "I like having an opinion and membership in the 
groups existing on those networks" with a percentage of $36.6 \%$, followed by "They help me create homogeneous groups of users, who share common interests" with a percentage of $33.0 \%$.

Table 5

The Reasons of Using Social Media

\begin{tabular}{llc}
\hline Reasons of use & freq & $\%$ \\
\hline Enable viewing news, information and opinions first and foremost. & 157 & $82.2 \%$ \\
Help establish social relations and bonds. & 133 & $69.6 \%$ \\
I like interacting, discussing and speaking with colleagues and network users. & 115 & $60.2 \%$ \\
For employing several tools including texts, images and videos. & 111 & $58.1 \%$ \\
They help me know the interests of others. & 100 & $52.4 \%$ \\
I like having an opinion and membership in the groups existing on those networks. & 70 & $36.6 \%$ \\
They help me create homogenous groups of users, who share common interests. & 63 & $33.0 \%$ \\
\hline
\end{tabular}

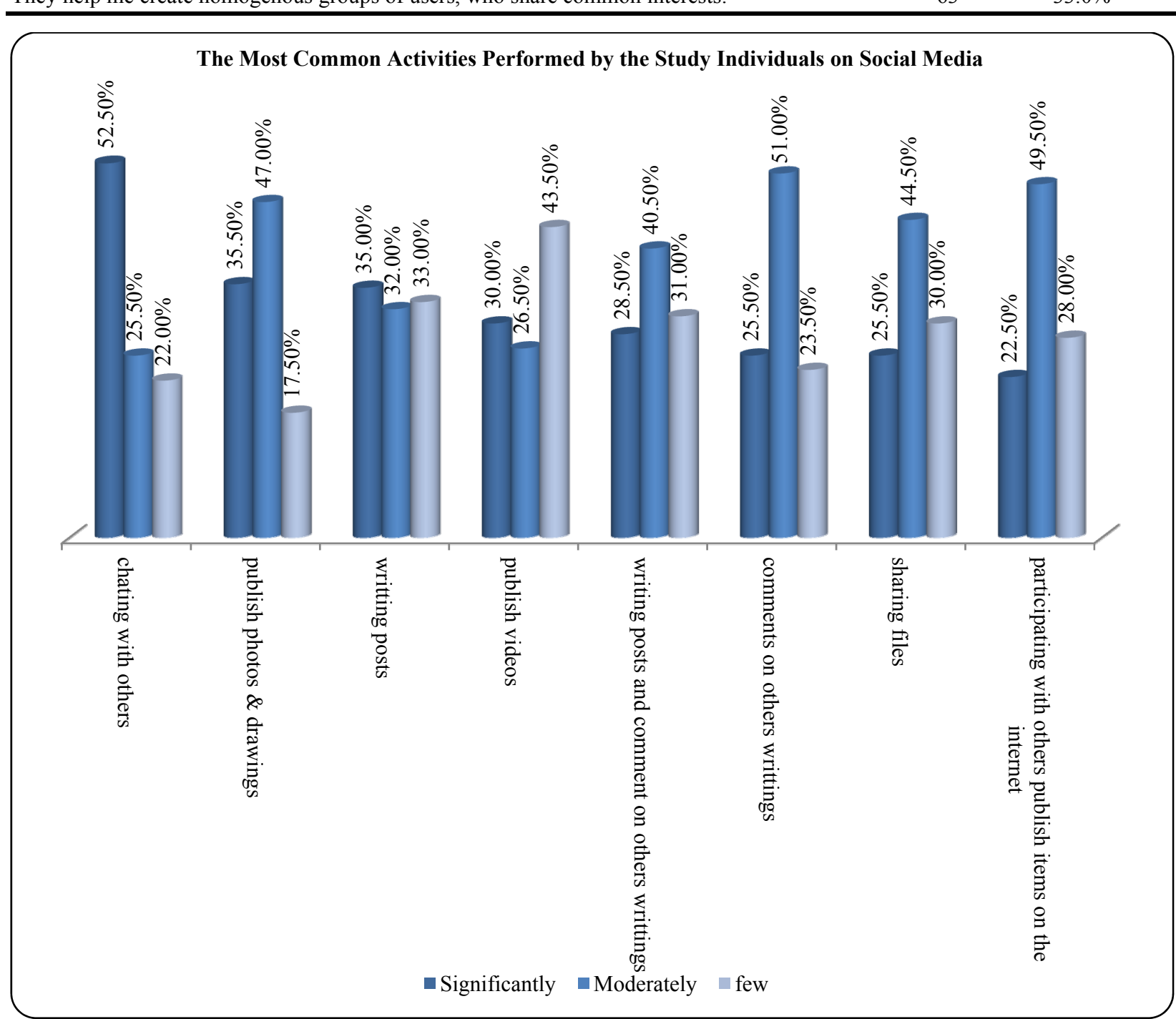

Figure 5. The most common activities performed by the study individuals on social media.

It is evident through Figure 5 that the most common activities performed by the study individuals on social media are ordered as follows: 
Using chat with others reached a percentage of $52.50 \%$, followed by "sharing images and photos" with a percentage of $47.00 \%$, and it took the second position, followed by the third position of "writing posts" with a percentage of $35.00 \%$; whereas "sharing videos" took the fourth position with a percentage of $30.0 \%$, followed by "writing posts and commenting on what is written by others" $28.5 \%$, followed by "commenting on what is written by others" with a percentage of $25.5 \%$, followed by "sharing files" with a percentage of $25.5 \%$ and "sharing what is posted on social media" with others $22.50 \%$. This result indicates that the most important activity performed by the study individuals is "chatting with others", i.e., "communicating with others".

(6) Describing Participation of the Study Individuals in terms of Conversations on Social Media:

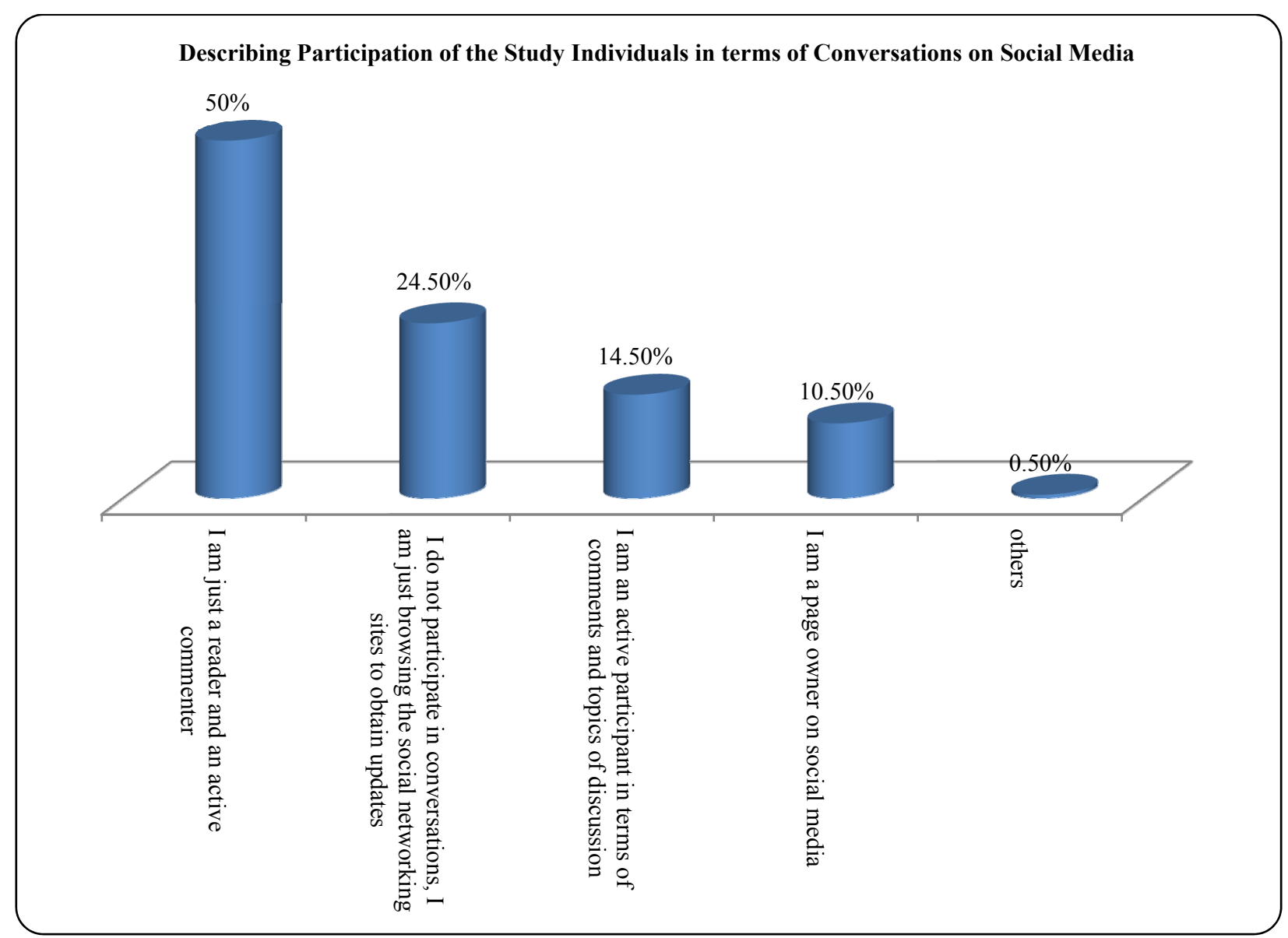

Figure 6. Describing participation of the study individuals in terms of conversations on social media.

It is evident through Figure 6 "Describing Participation of the Study Individuals in terms of Conversations on Social Media", according to the following order: "I am just a reader and an active commenter" with a percentage of $50 \%$, "I do not participate in conversations" with a percentage of $24.50 \%$, and "I am just browsing the social networking sites to obtain updates", followed by "I am an active participant in terms of comments and topics of discussion" with a percentage of $14.50 \%$, followed by "I am a page owner on social media" with a percentage of $0.50 \%$. It shows the most important description of the sample individuals' conversations on social media, which is represented in "I am a reader and commenter", and it got the highest percentage.

(7) Motives of Using Social Media: 
Table 6

The Motives of Using Social Media

\begin{tabular}{|c|c|c|c|c|c|c|}
\hline \multirow{2}{*}{ Motives } & \multicolumn{2}{|c|}{ Always } & \multicolumn{2}{|c|}{ Sometimes } & \multicolumn{2}{|c|}{ Rarely } \\
\hline & freq & $\%$ & freq & $\%$ & freq & $\%$ \\
\hline Knowing opinions of others on the various issues of society, where I live. & 122 & $61.0 \%$ & 62 & $31.0 \%$ & 16 & $8.0 \%$ \\
\hline They allow creating links to other pages on the Internet. & 55 & $27.5 \%$ & 107 & $53.5 \%$ & 38 & $19.0 \%$ \\
\hline I can obtain information on topics that are of great interest to me. & 146 & $73.0 \%$ & 42 & $21.0 \%$ & 12 & $6.0 \%$ \\
\hline They enhance my emotional affairs. & 44 & $22.0 \%$ & 92 & $46.0 \%$ & 64 & $32.0 \%$ \\
\hline Getting to know personal profiles of the family and friends. & 99 & $49.5 \%$ & 66 & $33.0 \%$ & 35 & $17.5 \%$ \\
\hline Reviewing my inbox messages. & 132 & $66.0 \%$ & 49 & $24.5 \%$ & 19 & $9.5 \%$ \\
\hline They help me avoid others. & 45 & $22.5 \%$ & 91 & $45.5 \%$ & 64 & $32.0 \%$ \\
\hline For continuous communication with family and friends. & 139 & $69.5 \%$ & 43 & $21.5 \%$ & 18 & $9.0 \%$ \\
\hline They help me escape from pressures of life and reality. & 63 & $31.5 \%$ & 102 & $51.0 \%$ & 35 & $17.5 \%$ \\
\hline Searching for information easily. & 146 & $73.0 \%$ & 38 & $19.0 \%$ & 16 & $8.0 \%$ \\
\hline Finding several friends from outside the society in which I live. & 61 & $30.5 \%$ & 93 & $46.5 \%$ & 46 & $23.0 \%$ \\
\hline I can choose and follow topics having a high rate of follow up and evaluation. & 102 & $51.0 \%$ & 71 & $35.5 \%$ & 27 & $13.5 \%$ \\
\hline When I am depressed. & 46 & $23.0 \%$ & 67 & $33.5 \%$ & 87 & $43.5 \%$ \\
\hline Communicating with people who cannot be reached easily. & 95 & $47.5 \%$ & 67 & $33.5 \%$ & 38 & $19.0 \%$ \\
\hline Sharing photos and videos with family and friends. & 120 & $60.0 \%$ & 61 & $30.5 \%$ & 19 & $9.5 \%$ \\
\hline Part of my daily routine when I use the Internet. & 109 & $54.5 \%$ & 74 & $37.0 \%$ & 17 & $8.5 \%$ \\
\hline They help me forget the pressures of studying. & 95 & $47.5 \%$ & 72 & $36.0 \%$ & 33 & $16.5 \%$ \\
\hline I find on them information that I do not find on other sites. & 97 & $48.5 \%$ & 77 & $38.5 \%$ & 26 & $13.0 \%$ \\
\hline When I do not want to be alone. & 98 & $49.0 \%$ & 68 & $34.0 \%$ & 34 & $17.0 \%$ \\
\hline Because they amuse me in a cheerful manner. & 126 & $63.0 \%$ & 58 & $29.0 \%$ & 16 & $8.0 \%$ \\
\hline They fill my free time and destroy boredom. & 131 & $65.5 \%$ & 51 & $25.5 \%$ & 18 & $9.0 \%$ \\
\hline Knowing many things that I had not known before. & 133 & $66.5 \%$ & 48 & $24.0 \%$ & 19 & $9.5 \%$ \\
\hline Information on others. Getting & 78 & $39.0 \%$ & 102 & $51.0 \%$ & 20 & $10.0 \%$ \\
\hline I can learn new skills and get to know new locations. & 113 & $56.5 \%$ & 63 & $31.5 \%$ & 24 & $12.0 \%$ \\
\hline Following up current events. & 91 & $45.5 \%$ & 84 & $42.0 \%$ & 25 & $12.5 \%$ \\
\hline An alternative for mass media. & 97 & $48.5 \%$ & 71 & $35.5 \%$ & 32 & $16.0 \%$ \\
\hline They enhance my integration into society. & 91 & $45.5 \%$ & 75 & $37.5 \%$ & 34 & $17.0 \%$ \\
\hline Introducing topics that can be discussed. & 100 & $50.0 \%$ & 68 & $34.0 \%$ & 32 & $16.0 \%$ \\
\hline
\end{tabular}

Table 6 shows the most important motives, which encourage the study individuals to use social media according to the following order:

1. "I can obtain information on topics that are of great interest to me" since the percentage of those, who said that this "Always" represented their motive, reached $73 \%$.

2. "Searching for information easily", as the percentage of those, who said that this "Always" represented their motive, reached $73 \%$, "for continuous communication with family and friends", as the percentage of those, who said that this "Always" represented their motive, reached 59.9\%, "Knowing many things that I had not known before", since the percentage of those, who said that this "Always" represented their motives, reached $66.5 \%$, "reviewing my inbox messages", since the percentage of those, who said that this "Always" represented their motive, reached 66\%, "they fill my free time and destroy boredom", since the percentage of those, who said that this "Always" represented their motive, reached $65.5 \%$.

3. "Because they amuse me in a cheerful manner", since the percentage of those, who said that this "Always" represented their motive, reached $63 \%$, "Knowing opinions of others on the various issues of society, where I 
live", since the percentage of those, who said that this "Always" represented their motive, reached $61 \%$, "sharing photos and videos with family and friends", since the percentage of those, who said that this "Always" represented their motive, reached $60 \%$, "I can learn new skills and get to know new locations", as the percentage of those, who said that this "Always" represented their motive, reached 56.5\%, "part of my daily routine when I use the Internet", as the percentage of those, who said that this "Always" represented their motive, reached 54.5\%, "I can choose and follow topics having a high rate of follow up and evaluation", as the percentage of those, who said that this "Always" represented their motive, reached 51\%, "Introducing topics that can be discussed", as the percentage of those, who said that this "Always" represented their motive, reached $50 \%$, "Getting to know personal profiles of the family and friends", as the percentage of those, who said that this "Always" represented their motive, reached 49.5\%, "when I do not want to be alone", as the percentage of those, who said that this "Always" represented their motive, reached 49\%, "I find on them information that I do not find on other sites", as the percentage of those, who said that this "Always" represented their motive, reached $48.5 \%$, "an alternative for mass media", as the percentage of those, who said that this "Always" represented their motive, reached $48.5 \%$, "Communicating with people who cannot be reached easily", as the percentage of those, who said that this "Always" represented their motive, reached $47.5 \%$, "they help me forget the pressures of studying", as the percentage of those, who said that this "Always" represented their motive, reached $47.5 \%$, "following up current events", as the percentage of those, who said that this "Always" represented their motive, reached $45.5 \%$, "they enhance my integration into society", as the percentage of those, who said that this "Always" represented their motive, reached $45.5 \%$, "knowing information on others", as the percentage of those, who said that this "Always" represented their motive, reached 39\%, "they help me escape from the pressures of life and reality", as the percentage of those, who said that this "Always" represented their motive, reached $31.5 \%$, "finding several friends from outside the society in which I live", as the percentage of those, who said that this "Always" represented their motive, reached 30.5\%, "they allow creating links to other pages on the Internet", as the percentage of those, who said that this "Always" represented their motive, reached 27.5\%, "when I am depressed", as the percentage of those, who said that this "Always" represented their motive, reached $23 \%$, "they help me avoid others", as the percentage of those, who said that this "Always" represented their motive, reached $22.5 \%$, "they enhance my emotional affairs", as the percentage of those, who said that this "Always represented their motive", reached $22 \%$. The foregoing illustrates that "obtaining information and communicating with others" came on top of the motives of using social media, followed by entertainment and amusement, then education, followed by various motives; including "being part of the daily routine" etc.

(8) Satisfactions Achieved by the Study Individuals through Their Usage of Social Media:

It is evident through Table 7 that the satisfactions achieved by the study individuals through their usage of social media came according to the following order:

1. "They helped to entertain me", as the percentage of those, who said that this "Always" represented a satisfaction for them, reached 68\%, "They filled my leisure time", as the percentage of those, who said that this "Always" represented a satisfaction for them, reached $64.5 \%$, "They always keep me in touch with others", as the percentage of those, who said that this "Always" represented a satisfaction for them, reached $61.5 \%$, "They increased my knowledge relevant to different issues raised in society", as the percentage of those, who said that this "Always" represented a satisfaction for them, reached $60.5 \%$, "I can reach my friends no matter how far the distance between us", as the percentage of those, who said that this "Always" represented a satisfaction for them, reached $60 \%$, "They enabled me to know new tourist destinations", as the percentage of those, who said 
that this "Always" represented a satisfaction for them, reached 58\%, "They enable me to choose the group to which I want to talk easily", as the percentage of those, who said that this "Always" represented a satisfaction for them, reached 55\%, "They enhanced my integration into society", as the percentage of those, who said that this "Always" represented a satisfaction for them, reached 53.5\%, "I can learn new skills", as the percentage of those, who said that this "Always" represented a satisfaction for them, reached 51.5\%, "They make me feel close to family and friends", as the percentage of those, who said that this "Always" represented a satisfaction for them, reached 51.5\%, "They enable me to express my opinions freely", as the percentage of those, who said that this "Always" represented a satisfaction for them, reached 51.5\%, "They enable me to get acquainted to cultures and traditions of other people", as the percentage of those, who said that this "Always" represented a satisfaction for them, reached 50.5\%, "They increased the number of my friends from outside the society, where I live", as the percentage of those, who said that this "Always" represented a satisfaction for them, reached $49.5 \%$, "They helped me not to feel lonely", as the percentage of those, who said that this "Always" represented a satisfaction for them, reached $46 \%$, "They make me forget the pressures of life", as the percentage of those, who said that this "Always" represented a satisfaction for them, reached $45.5 \%$, "They helped me to relax", as the percentage of those, who said that this "Always" represented a satisfaction for them, reached 37\%, "They helped me escape from my problems", as the percentage of those, who said that this "Always" represented a satisfaction for them, reached $27 \%$, "They make me feel emotionally desired", as the percentage of those, who said that this represented a satisfaction for them, reached $24.5 \%$. The foregoing illustrates the most prominent satisfactions achieved through the usage of social media, which are represented in entertainment, spending leisure time and communicating with others. There were low percentages of those, who said that they achieve satisfactions related to relaxation, escaping from problems and feeling emotionally desired.

Table 7

The Satisfactions Achieved Through the Usage of Social Media

\begin{tabular}{|c|c|c|c|c|c|c|}
\hline \multirow{2}{*}{ Satisfactions } & \multicolumn{2}{|c|}{ Always } & \multicolumn{2}{|c|}{ Sometimes } & \multicolumn{2}{|c|}{ Rarely } \\
\hline & freq & $\%$ & freq & $\%$ & freq & $\%$ \\
\hline They increased my knowledge relevant to different issues raised in society. & 121 & $60.5 \%$ & 67 & $33.5 \%$ & 12 & $6.0 \%$ \\
\hline They enable me to get acquainted to cultures and traditions of other people. & 101 & $50.5 \%$ & 88 & $44.0 \%$ & 11 & $5.5 \%$ \\
\hline They make me feel emotionally desired. & 49 & $24.5 \%$ & 64 & $32.0 \%$ & 87 & $43.5 \%$ \\
\hline They helped me not to feel lonely. & 92 & $46.0 \%$ & 71 & $35.5 \%$ & 37 & $18.5 \%$ \\
\hline They helped me to relax. & 74 & $37.0 \%$ & 95 & $47.5 \%$ & 31 & $15.5 \%$ \\
\hline They enhanced my integration into society. & 107 & $53.5 \%$ & 63 & $31.5 \%$ & 30 & $15.0 \%$ \\
\hline Enabled me to know new tourist destinations. & 116 & $58.0 \%$ & 62 & $31.0 \%$ & 22 & $11.0 \%$ \\
\hline Helped me escape from my problems. & 54 & $27.0 \%$ & 84 & $42.0 \%$ & 62 & $31.0 \%$ \\
\hline I can learn new skills. & 103 & $51.5 \%$ & 70 & $35.0 \%$ & 27 & $13.5 \%$ \\
\hline They make me feel close to family and friends. & 103 & $51.5 \%$ & 68 & $34.0 \%$ & 29 & $14.5 \%$ \\
\hline They make me forget the pressures of life. & 91 & $45.5 \%$ & 74 & $37.0 \%$ & 35 & $17.5 \%$ \\
\hline They always keep me in touch with others. & 123 & $61.5 \%$ & 57 & $28.5 \%$ & 20 & $10.0 \%$ \\
\hline They increased the number of my friends from outside the society, where I live. & 99 & $49.5 \%$ & 60 & $30.0 \%$ & 41 & $20.5 \%$ \\
\hline I can reach my friends no matter how far the distance between us. & 120 & $60.0 \%$ & 56 & $28.0 \%$ & 24 & $12.0 \%$ \\
\hline They enable me to choose the group to which I want to talk easily. & 110 & $55.0 \%$ & 62 & $31.0 \%$ & 28 & $14.0 \%$ \\
\hline They helped to entertain me. & 136 & $68.0 \%$ & 45 & $22.5 \%$ & 19 & $9.5 \%$ \\
\hline They enable me to express my opinions freely. & 103 & $51.5 \%$ & 74 & $37.0 \%$ & 23 & $11.5 \%$ \\
\hline They filled my leisure time. & 129 & $64.5 \%$ & 50 & $25.0 \%$ & 21 & $10.5 \%$ \\
\hline
\end{tabular}


(9) Satisfactions Achieved Through the Usage of Social Media According to Gender.

Table 8

Differences in Satisfactions Achieved Through the Usage of Social Media According to Gender

\begin{tabular}{|c|c|c|c|}
\hline Satisfactions & Average & $\begin{array}{l}\mathrm{T} \text { Value } \\
\mathrm{T} \text { Test }\end{array}$ & P Value \\
\hline They increased my knowledge relevant to different issues raised in society. & $\begin{array}{l}1.48 \\
1.44\end{array}$ & 0.469 & 0.640 \\
\hline They enable me to get acquainted to cultures and traditions of other people. & $\begin{array}{l}1.62 \\
1.50\end{array}$ & 1.373 & 0.171 \\
\hline They make me feel emotionally desired. & $\begin{array}{l}2.01 \\
2.30\end{array}$ & -2.494 & 0.013 \\
\hline They helped me not to feel lonely. & $\begin{array}{l}1.70 \\
1.74\end{array}$ & -0.350 & 0.727 \\
\hline They helped me to relax. & $\begin{array}{l}1.74 \\
1.81\end{array}$ & -0.721 & 0.472 \\
\hline They enhanced my integration into society. & $\begin{array}{l}1.74 \\
1.54\end{array}$ & 1.921 & 0.056 \\
\hline They enabled me to know new tourist destinations. & $\begin{array}{l}1.57 \\
1.50\end{array}$ & 0.674 & 0.501 \\
\hline They helped me escape from my problems. & $\begin{array}{l}2.03 \\
2.05\end{array}$ & -0.205 & 0.838 \\
\hline I can learn new skills. & $\begin{array}{l}1.78 \\
1.52\end{array}$ & 2.533 & 0.012 \\
\hline They make me feel close to family and friends. & $\begin{array}{l}1.64 \\
1.63\end{array}$ & 0.098 & 0.922 \\
\hline They make me forget the pressures of life. & $\begin{array}{l}1.83 \\
1.65\end{array}$ & 1.678 & 0.095 \\
\hline They always keep me in touch with others. & $\begin{array}{l}1.62 \\
1.40\end{array}$ & 2.328 & 0.021 \\
\hline They increased the number of friends from outside the society, where I live. & $\begin{array}{l}1.87 \\
1.61\end{array}$ & 2.302 & 0.022 \\
\hline I can reach my friends no matter how far the distance between us. & $\begin{array}{l}1.74 \\
1.38\end{array}$ & 3.619 & 0.000 \\
\hline They enable me to choose the group to which I want to talk easily. & $\begin{array}{l}1.74 \\
1.50\end{array}$ & 2.348 & 0.020 \\
\hline They helped to entertain me. & $\begin{array}{l}1.60 \\
1.30\end{array}$ & 3.164 & 0.002 \\
\hline They enable me to express my opinions freely. & $\begin{array}{l}1.74 \\
1.51\end{array}$ & 2.308 & 0.022 \\
\hline They filled my leisure time. & $\begin{array}{l}1.60 \\
1.37\end{array}$ & 2.289 & 0.023 \\
\hline
\end{tabular}

Table 8 indicates that there are no statistically significant differences between males and females. In terms of the phrase: "They increased my knowledge relevant to different issues raised in society", the meaningful value is $0.05<0.640$, in terms of the phrase: "They enable me to get acquainted to cultures and traditions of other people", the meaningful value is $0.05<0.171$, regarding the phrase: "They helped me not to feel lonely", the meaningful value is $0.05<0.727$, regarding the phrase: "They helped me to relax", the meaningful value is $0.05<0.472$, regarding the phrase: "They enhanced my integration into society", the meaningful value is 0.05 
$<0.056$, regarding the phrase: "They enabled me to know new tourist destinations", the meaningful value is $0.05<0.501$, regarding the phrase: "They helped me escape from my problems", the meaningful value is 0.05 $<0.838$, regarding the phrase: "They make me feel close to family and friends", the meaningful value is $0.05<$ 0.922 , regarding the phrase: "They make me forget the pressures of life", the meaningful value is $0.05<0.095$, while there was a statistically significant relation between both (male and female) genders. In terms of the phrase: "They make me feel emotionally desired", the meaningful value is $0.05>0.013$, regarding the phrase: "I can learn new skills", the meaningful value is $0.05>0.012$, regarding the phrase: "They always keep me in touch with others", the meaningful value is $0.05>0.021$, regarding the phrase: "They increased the number of friends from outside the society, where I live", the meaningful value is $0.05>0.022$, regarding the phrase: "I can reach my friends no matter how far the distance between us", the meaningful value is $0.05>0.000$, regarding the phrase: "They enable me to choose the group to which I want to talk easily", the meaningful value is $0.05>0.022$, regarding the phrase: "They helped to entertain me", the meaningful value is $0.05>$ 0.002 , regarding the phrase: "They enable me to express my opinions freely", the meaningful value is $0.05>$ 0.022 , and regarding the phrase: "They filled my leisure time", the meaningful value is $0.05>0.023$.

(10) The Most Apparent Disadvantages of Social Media from the Study Individuals' Point of View:

Table 9

The Most Apparent Disadvantages of Social Media From the Study Individuals' Point of View

\begin{tabular}{|c|c|c|c|c|c|c|}
\hline \multirow[b]{2}{*}{ The most apparent disadvantages of social media } & \multicolumn{2}{|c|}{ Agree } & \multicolumn{2}{|c|}{ Neutral } & \multicolumn{2}{|c|}{ Disagree } \\
\hline & freq & $\%$ & freq & $\%$ & freq & $\%$ \\
\hline A waste of Time. & 110 & $55.0 \%$ & 67 & $33.5 \%$ & 23 & $11.5 \%$ \\
\hline They help in spreading rumors. & 136 & $68.0 \%$ & 52 & $26.0 \%$ & 12 & $6.0 \%$ \\
\hline Considering them an entertaining method rather than being cultural. & 109 & $54.5 \%$ & 66 & $33.0 \%$ & 25 & $12.5 \%$ \\
\hline Lack of privacy. & 77 & $38.5 \%$ & 105 & $52.5 \%$ & 18 & $9.0 \%$ \\
\hline Lack of confidence in information shared via those methods. & 100 & $50.0 \%$ & 78 & $39.0 \%$ & 22 & $11.0 \%$ \\
\hline They make you feel shocked by knowing the opinions of your colleagues. & 71 & $35.5 \%$ & 104 & $52.0 \%$ & 25 & $12.5 \%$ \\
\hline $\begin{array}{l}\text { They can be used in spreading negative behaviors"; such as molestation, } \\
\text { bullying and offending others. }\end{array}$ & 111 & $55.5 \%$ & 59 & $29.5 \%$ & 30 & $15.0 \%$ \\
\hline Expensive in case of the desire to overuse them. & 64 & $32.0 \%$ & 93 & $46.5 \%$ & 43 & $21.5 \%$ \\
\hline They cause negative feelings and attitudes in case of using them extremely. & 103 & $51.5 \%$ & 73 & $36.5 \%$ & 24 & $12.0 \%$ \\
\hline They lead to isolation. & 105 & $52.5 \%$ & 73 & $36.5 \%$ & 22 & $11.0 \%$ \\
\hline
\end{tabular}

Table 9 shows the most apparent disadvantages of social media from the study individuals' point of view. It is evident through the previous table that the most apparent disadvantages of social media from the study individuals' point of view appeared according to the following order:

1. "They help in spreading rumors" as a percentage of $68 \%$ agreed on this, "They can be used in spreading negative behaviors"; such as "molestation, bullying and offending others", as a percentage of $55.5 \%$ agreed on this, "Waste of time", as a percentage of 55\% agreed on this, "Considering them an entertaining method rather than being cultural", as a percentage of $54.5 \%$ agreed on this, "They lead to isolation" as a percentage of $52.5 \%$ agreed on this, "They cause negative feelings and attitudes in case of using them extremely", as a percentage of $51.5 \%$ agreed on this, "lack of confidence in information shared via those methods", as a percentage of 50\% agreed on this, "lack of privacy", as a percentage of $38.5 \%$ agreed on this, "they make you feel shocked by knowing the opinions of your colleagues", as a percentage of 35.5\% agreed on this, "Expensive in case of the desire to overuse them", as a percentage of $32 \%$ agreed on this. The above-mentioned comments indicate that 
there are disadvantages relevant to social media, in terms of spreading rumors, using them in spreading negative behaviors, considering them a waste of time, while there was a low percentage of those, who said that they hinder privacy, being in conflict with colleagues and being expensive.

(11) Differences between the Sample of Study in terms of Gender, and their Opinions about the most apparent Disadvantages of Social Media:

Table 10

The Most Apparent Disadvantages of Social Media in Terms of the Opinions of Both Males and Females

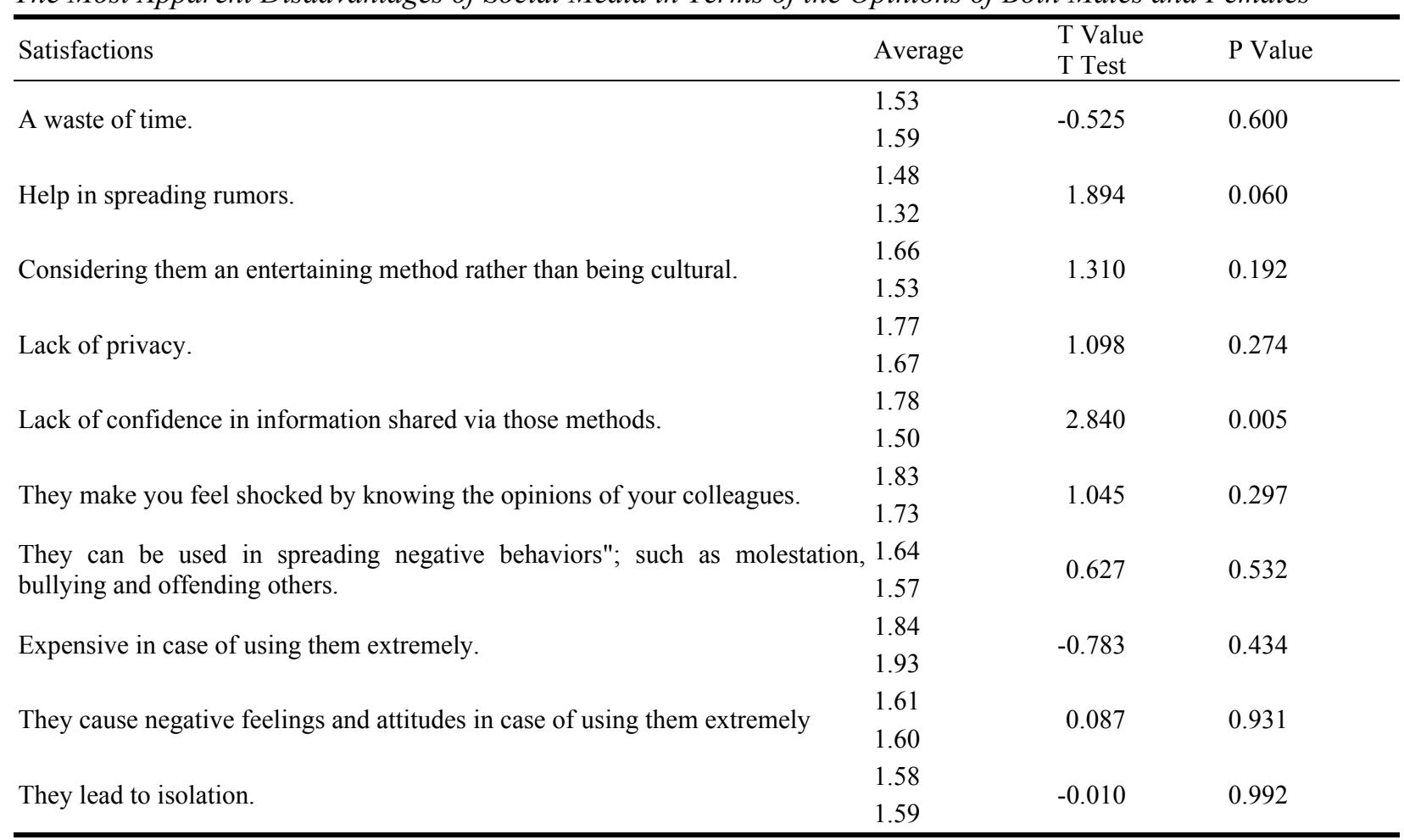

Table 10 indicates that there are no statistically significant differences between males and females. Regarding the phrase: "A waste of time", the meaningful value is $0.05<0.600$, the phrase: "Help in spreading rumors", the meaningful value is $0.05<0.060$, the phrase: "considering them an entertaining method rather than being cultural", the meaningful value is $0.05<0.192$, the phrase: "lack of privacy", the meaningful value is $0.05<0.274$, the phrase: "They make you feel shocked by knowing the opinions of your colleagues", the meaningful value is $0.05<0.297$, the phrase: "They can be used in spreading negative behaviors; such as molestation, bullying and offending others", the meaningful value is $0.05<0.532$, the phrase: "Expensive in case of using them extremely", the meaningful value is $0.05<0.434$, the phrase: "They cause negative feelings and attitudes in case of using them extremely", the meaningful value is $0.05<0.931$, the phrase: "They lead to isolation", the meaningful value is $0.05<0.992$, while there was a statistically significant relation between the gender (male and female), and in terms of the phrase: "Lack of confidence in information shared via those methods", the meaningful value is $0.05<0.005$.

\section{Conclusion}

Results of the study illustrated the following: 
- A high percentage of Emirati Youth 77.5\% mentioned that they always use those social media.

- The percentage of males, who always use social media reached $38.5 \%$, while the percentage of females reached $61 \%$, as the meaningful value reached $0.05<0.044$, and there are no statistically significant differences between males and females in terms of the extent of using social media.

- Home is the most preferred place for using social media ( $85.40 \%$ mentioned that).

- Most of the study individuals can make a balance between spending time on Internet and spending time with people outside the world of Internet.

- There were higher percentages of those, who said that social media had a positive impact on them than those, who said that social media had a negative impact on them.

- Among the most prominent usages of social media by Emirati youth are: being acquainted with news right away, while most of them focused on using "chat", followed by sharing photos and images.

- Most of the sample of study "The Youth" mentioned that "they are just readers and commenters in terms of what is posted on social media".

- Among the most important motives of using social media are: "obtaining information and communicating with others", which came on top of the motives of using social media, followed by "entertainment and amusement", then "education", followed by various motives including that "they are part of the daily routine", etc.

- The most significant satisfactions achieved by the Emirati youth through using social media, are represented in entertainment, spending leisure time and communicating with others, and there was a lower percentage of those, who said that they achieved satisfactions related to relaxation, escaping from problems, and feeling emotionally desired.

- Among the most apparent disadvantages noticed by the Emirati youth in social media are: spreading rumors and using them in spreading negative behaviors and considering them a waste of time, and there were low percentages of those, who mentioned that they hinder privacy, cause conflict with colleagues and being expensive.

The most important recommendations:

- Social networking sites must be employed in order to become an efficient positive method of communication in the society.

- The role of parents is represented in highlighting the dangers of social media, their negative effect on their children, how to achieve the utmost benefit from them.

- Conducting more studies on the role of social media in general through polarizing all categories of society due to the great importance of them in their lives.

- Establishing a local social networking site that can enhance communication among youth in the Emirati and Arab societies in order to contribute to increase the opportunities of establishing a variety of information sources and disseminating culture among them.

- Maintaining students' privacy on those social media through issuing legislations that prohibit using those social media against them whatsoever.

- Holding more meaningful scientific seminars that highlight the negative impact of social media on social values and behaviors.

- Emirati universities must continuously give special attention to the study of social media's impact on youth regarding their behaviors, values, concepts, culture and local identity. 


\section{References}

Al-Amudi, G. B. A. A. (2013). Social software in the web-certified educational system: Social Networks-A model. Proceedings from The First International Conference of Electronic Learning and Distant Learning - Learning Industry for the Future, Kingdom of Saudi Arabia - Riyadh.

Al-Omari, A. B. H. (2008). Internet addiction and some of its psychological and social impacts on the secondary-stage students, management of education, hail educational governorate (An Unpublished Master's Thesis, King Khalid University, Abha, Saudi Arabia).

Bălterețu, C. M., \& Balaban, D. (2010). Cristinam motivation in using social network sites by Romanian students: A Qualitative Approach. Journal of Media Research, 3(1), 67-74.

El-Bary, W. A. (2009). Technology of communication and social change: Developmental dimensions of informatics. Provrrdings from The International Conference of Communication Techniques and Social Change, King Saud University.

Hall, A. (2009). College students' motives for using social network sites and their relationships to users' personality traits. Retrieved November 2, 2010, from http://web.ebscohost.com/ehost/resultsadvanced?

Hansen, K. A., Neuzil, M., \& Ward, J. (2011). Newspaper training program shows gains in social media. Newspaper Research Journal, 32(3), 40-50.

Jamal Al-Minais, J. (2015). Results relevant to the intensive usage of social networking sites among the Kuwaiti youth. Gulf Studies and Arab Island Magazine (p. 157).

Jennifer, B. C. (2014). Twitter, Facebook, Blogs, and Media sharing sites in the Classroom. In H. Al Deen \& J. Hendricks (Eds.), Social Media. UK: Lexington Books.

Kalpidou, M., Costin, D., \& Morris, J. (2011). The relationship between Facebook and the well-being of undergraduate college students. Cyber Psychology, Behavior and Social Networking, 14(4), 183-189.

Kayahara, J., \& Wellman, B. (2007). Searching for culture-High and low. Retrieved December 2, 2010, from $\mathrm{ttp}: / / \mathrm{jcmc}$.indiana.edu/ vol12/issue3/ kayahara.html

Lee, E., Lee, L., \& Jang, J. (2011). Internet for the internationals: Effects of Internet use motivations on international students college adjustment, cyber psychology. Behavior and Social Networking, 14(7-8), 433-437.

Lei, L., \& Wu, Y. (2007). Adolescents paternal attachment and internet use. Cyber Psychology \& Behavior, 10(5), 633-640.

Mekkawi, H. E., \& Al-Sayed, L. H. (1998). Communication and its contemporary theories (p. 248). Cairo: Egyptian-Lebanese Publishing House.

Noor Al-Deen, H. S., \& Hendricks, J. A. (2014). Facebook: How college students work it. Retrieved from https://rowman.com/ISBN/978-0-7391-6730-4

Sangari, E., Limayem, M., \& Rouis, S. (2011). Impact of Face book usage on students' academic achievement: Role of self-regulation and trust. Electronic Journal of Research in Educational Psychology, 9(3), 961-994.

Sheldon, P. (2008). Student favorite: Facebook and motives for its use. Southwestern Mass Communication Journal, $23(2), 39-53$.

Tia, T. (2014). Using social media and creating social media courses. In H. Al Deen \& J. Hendricks (Eds.), Social Media. UK: Lexington Books.

Urista, M. A., Dong, Q. W., \& Day, K. D. (2009). Explaining why young adults use Myspace and Facebook through Uses \& Gratification theory. Human Communication, 12(2), 215-229. 